\title{
Evaluation of a School-Based Health Education Program for Urban Indigenous Young People in Australia
}

\author{
Claire Malseed ${ }^{1,2 *}$, Alison Nelson ${ }^{1,2}$, Robert Ware ${ }^{1,3}$ \\ ${ }^{1}$ The Institute for Urban Indigenous Health, Brisbane, Australia \\ ${ }^{2}$ Aboriginal and Torres Strait Islander Studies Unit, The University of Queensland, Brisbane, Australia \\ ${ }^{3}$ School of Population Health, The University of Queensland, Brisbane, Australia \\ Email: ${ }^{*}$ clairemalseed@gmail.com
}

Received 20 January 2014; revised 26 February 2014; accepted 5 March 2014

Copyright (C) 2014 by authors and Scientific Research Publishing Inc.

This work is licensed under the Creative Commons Attribution International License (CC BY).

http://creativecommons.org/licenses/by/4.0/

(c) (i) Open Access

\section{Abstract}

The aim of this study was to investigate the effectiveness of a school-based health promotion and education program in improving knowledge, attitudes, self-efficacy and behaviours of urban Indigenous young people regarding chronic disease and associated risk factors. A mixed methods approach was adopted for this evaluation; however, this paper will focus on the quantitative aspect of the study. The Deadly Choices ${ }^{\mathrm{TM}}$ health education program was delivered weekly at six education facilities in Brisbane, Australia to participants from years seven to 12 over seven weeks. One school that received the Deadly Choices program the following term acted as the control group. Questionnaire data was collected immediately pre and post intervention to assess program impact. As self-reported by participants there were mostly significant improvements over time for questions relating to knowledge, attitudes and self-efficacy regarding leadership, chronic disease and risk factors within the intervention group. There were also significant changes within the intervention group regarding breakfast frequency $(P=0.002)$, physical activity frequency $(P \leq$ $0.001)$, fruit $(P=0.004)$ and vegetable $(P \leq 0.001)$ intake. Overall, there were few significant differences between the control and intervention groups regarding health attitudes and behaviours; however, there were considerably more improvements relating to self-efficacy and knowledge of chronic disease and associated risk factors between groups. The program also facilitated 30 Aboriginal and Torres Strait Islander health checks for participants. Deadly Choices is an innovative and comprehensive school-based program which has great potential to improve the health outcomes of Indigenous young people in urban areas by providing education in leadership and chronic disease prevention; engaging students in physical activity participation; and collaborating with health services to facilitate health checks.

\footnotetext{
${ }^{*}$ Corresponding author.
} 


\section{Keywords}

\section{School-Based Health Promotion; Chronic Disease; Indigenous Health; Young People; Australia}

\section{Introduction}

Indigenous Australian ${ }^{1}$ people continue to experience a disproportionately high burden of chronic disease compared to other Australians [1]. Chronic disease and related factors account for $70 \%$ of the health gap between Indigenous and non-Indigenous Australians [2]. Indigenous young people experience an excess burden of preventable and treatable disease such as ear disease, poor oral health and recurrent infections [3] and have high rates of risk factors for the development of chronic diseases in adulthood [4]. Data shows that the onset of chronic disease is likely to occur at a much younger age among Indigenous Australians than non-Indigenous Australians [5]. These chronic diseases have common risk factors including smoking, poor nutrition, alcohol misuse, inadequate physical activity and overweight and obesity [6]. Economic and social determinants of poor Indigenous health further contribute to the high burden of chronic disease in the Indigenous Australian population [7].

Schools are widely recognised as important settings for the delivery of health education to young people [8] [9]. Schools have continuous, intensive contact with large numbers of young people, providing the ideal setting to shape the health knowledge, attitudes, self-efficacy and behaviours of young people [10] [11]. According to the World Health Organisation's "Health Promoting Schools Framework”, positive health outcomes for youth can be achieved when schools adopt a whole-of-school approach to health initiatives [12]. However, some studies suggest that for disadvantaged or minority groups, targeted interventions may also be required to provide additional support for young people to improve health behaviours [11] [13]. For Indigenous young people, research suggests that the adoption of a strengths-based approach, which focuses on the abilities, knowledge, capacities, and cultural resources of participants, is essential in health promotion programs targeting this group [14] [15].

Nationally and internationally, numerous small and large-scale school-based health education interventions have been evaluated [16]-[18]. However, studies vary considerably in terms of the study design used to conduct the evaluation, characteristics of the study participants, and measures used to assess participants' outcomes. A consequence of these differences in study design and participants is that findings can only be cautiously generalised in determining what makes an effective intervention for a targeted population group. More specifically, few school-based health education programs which target Indigenous Australian students have been evaluated [12], making it difficult to determine which are most appropriate and effective for improving knowledge and modifying the attitudes, self-efficacy and behaviours of Indigenous young people. The few evaluations conducted have largely focused on drugs and alcohol and most have targeted Indigenous young people in rural or remote schools [19]. As the majority of Indigenous young people live in non-remote areas of Australia [5], and chronic diseases are the main contributor to the health gap between Indigenous and non-Indigenous Australians [2], school-based health education programs, that seek to educate large numbers of Indigenous young people about chronic disease risk factors within an urban context, have considerable potential to contribute to the prevention of chronic disease in the Indigenous population.

The aim of this study was to investigate the effectiveness of a school-based program in improving knowledge, attitudes, self-efficacy and behaviours of urban Indigenous young people regarding chronic disease and associated risk factors. Both qualitative and quantitative data were collected; however, the focus of this paper is on the quantitative aspect of the research.

\section{Methods}

This study investigated the effectiveness of a school-based health program for Indigenous Australian students in Brisbane, Australia, between April and October 2013. The Deadly Choices ${ }^{\mathrm{TM}}$ program is a school-based chronic disease promotion and education program that encourages Indigenous young people to be positive role models

${ }^{1}$ In Australia the term “Indigenous” is used to refer to both Aboriginal and Torres Strait Islander peoples. 
in reshaping health, lifestyle and physical activity choices among family, friends and networks. In an Indigenous context, a "Deadly Choice" is a healthy choice. The program is based on the principle of empowering young people to make healthy choices and uses a strengths-based approach to reinforce to Indigenous young people that chronic diseases are not inevitable [15]. This approach is also informed by recent research that suggests programs seeking to promote healthy lifestyle behaviours in Indigenous youth must go beyond just telling young Indigenous people to make healthy choices, towards encouraging and supporting them with tools to actually make them [20]. The Deadly Choices program was developed in partnership with urban-Indigenous healthy lifestyle officers and since 2010 has been delivered to more than 250 Indigenous students across 20 schools and training centres throughout South East Queensland.

\subsection{Ethics}

Ethical approval for the study was obtained from The University of Queensland and The Education Queensland Human Research Ethics Committee. Gatekeeper approval was received from school principals prior to approaching students to be involved in the research. Informed consent was obtained from students and their guardians for their involvement in the research project.

\subsection{Study Setting and Participants}

The Deadly Choices health education program was delivered in the greater Brisbane area at four schools, one training academy and one education and training centre located within a youth detention centre. All students who received the program were from years 7 to 12 and aged 11 to 18 . One of the secondary schools who were due to receive the Deadly Choices program the following term acted as a control group, before having postprogram data collected for inclusion in pre/post analyses. The schools and training centres were selected due to the high number of Indigenous students attending these schools and their expressed interest in receiving the Deadly Choices program. Schools and centres were located in Brisbane areas with low to high levels of socioeconomic disadvantage according to Socio-Economic Indexes for Areas (SEIFA) data [21].

Brisbane is the capital of Queensland and the third most populous city in Australia, with a population of 2.1 million people. There are over 50,000 Aboriginal and Torres Strait Islander people living in Brisbane, making it the largest Indigenous community in Australia. This comprises 38\% of the state's share of Aboriginal and Torres Strait Islander people in Queensland [22]. The unemployment rate in Brisbane is 5.6\% and the economy has grown consistently in recent years [23].

\subsection{Intervention}

The Deadly Choices program was delivered once a week over a seven-week period. Each session was approximately 90 minutes in duration and involved an ice-breaker activity, an education component and participation in physical activity. The education component covered seven modules including leadership, chronic disease, physical activity, nutrition, smoking, harmful substances and health services. Information was presented using the Microsoft PowerPoint computer program, in addition to interactive activities. A summary of the Deadly Choices education component is presented in Table 1. Following the final session, participants were encouraged to have an Aboriginal and Torres Strait Islander health check (MBS item 715). At some schools a medical van utilising local Indigenous health clinic staff was organised so participants could have a health check at school. At other schools health checks were organised at the local Indigenous health clinic and necessary transport arrangements were made for students.

The physical activity component of the program primarily focused on participation, increasing self-efficacy and teamwork. At some physical activity sessions, participants were exposed to traditional Indigenous games, which offered an opportunity to experience cultural traditions in sport-related activities, focusing on the cultural assets of these young people [24]. Young Indigenous healthy lifestyle workers who were considered role models in the community facilitated all sessions. Facilitators remained with the same school for the duration of the program to build trust and rapport. To reward participants for their efforts and encourage program attendance, participants who attended all sessions received a Deadly Choices shirt.

\subsection{Outcome Measures}

A questionnaire across four key domains was used to evaluate the effectiveness of the Deadly Choices program. 
Table 1. Description of intervention components.

\begin{tabular}{|c|c|c|}
\hline Week & Module & Brief description of key factors addressed \\
\hline 1 & Leadership & $\begin{array}{l}\text { - The "Closing the gap" initiative } \\
\text { - Determining features of good leadership } \\
\text { - Identifying leaders in the community }\end{array}$ \\
\hline 2 & Chronic Disease & $\begin{array}{l}\text { - } \quad \text { Explanation of Chronic Disease } \\
\text { - Common types of Chronic Diseases } \\
\text { - Chronic Disease risk factors }\end{array}$ \\
\hline 3 & Physical Activity & $\begin{array}{l}\text { - } \quad \text { Benefits of physical activity } \\
\text { - } \quad \text { Identifying types of physical activity } \\
\text { - } \quad \text { Physical activity guidelines }\end{array}$ \\
\hline 4 & Nutrition & $\begin{array}{l}\text { - } \quad \text { The five food groups and portion sizes } \\
\text { - } \quad \text { Decreasing sugary drinks } \\
\text { - } \quad \text { Imprgy Balance } \\
\text { - Healthy meal options }\end{array}$ \\
\hline 5 & Smoking & $\begin{array}{l}\text { - Substances in a cigarette } \\
\text { - Smoking’s impact on the body } \\
\text { - } \\
\text { - } \text { Benvironmentits of not smoking }\end{array}$ \\
\hline 6 & Harmful Substances & $\begin{array}{l}\text { - } \quad \text { Explanation of harmful substances } \\
\text { - } \quad \text { Risug and alcohol effects on the body } \\
\text { - } \quad \text { Support available }\end{array}$ \\
\hline 7 & Health Services & $\begin{array}{l}\text { - Health checks } \\
\text { - } \text { Medicare } \\
\text { - } \text { Registering for “Close the gap” services } \\
\text { Local Indigenous health services }\end{array}$ \\
\hline
\end{tabular}

The questionnaire built upon an existing questionnaire used previously for program evaluation. The questionnaire was piloted on 30 Indigenous students from a school who completed the Deadly Choices program the term prior, to identify the time required to complete it, any ambiguous questions and any difficulties faced during completion. Minor changes were made to the language, content and clarity of the questionnaire so that it could be more easily read and understood by the Indigenous young people.

The four questionnaire domains included demographics, knowledge, attitudes/self-efficacy and behaviours. Demographic questions included age, gender, identity, suburb and school. Knowledge questions focused on chronic diseases, associated risk factors, health conditions caused by smoking, sugar content of soft-drinks, types of physical activity, elements of good leadership and health check components. Attitudes/self-efficacy questions related to leadership, chronic disease prevention, health checks and the importance of health promoting behaviours. Behaviour questions focused on leadership, physical activity participation, eating habits, smoking habits, use of alcohol, tobacco and other drugs, and engagement with health services.

\subsection{Procedure}

Participants completed the questionnaire twice, immediately prior to the first session and following the final session. Participants in the control group completed the pre- and post-questionnaire at intervals concurrent with participants in the intervention group, as well as following the final session of their Deadly Choices program when it was delivered the following term. Questionnaires were completed in classrooms under supervision of Deadly Choices facilitators and research staff. All participants completed the questionnaire in pen/paper format and were able to access literacy support from Deadly Choices and research staff if and when required. Questionnaires were matched using a randomly assigned identification number.

\subsection{Data Analysis}

Descriptive statistics are reported as mean (standard deviation) for continuous data and frequency (percentage) for categorical data. Program effectiveness was investigated using linear mixed-effects regression for continuous 
outcomes and logistic mixed-effects regression for binary outcomes. In all models intervention group (education program/control) and time (pre/post-program) were included as main effects, as well as an intervention-by-time interaction term. All models were adjusted for repeated measures at the individual level. The significance and correlation of the Deadly Choices program with knowledge, attitudes/self-efficacy and behaviours was also investigated. Analysis was undertaken using Stata statistical software v 12.0 (StataCorp, College Station, TX, USA).

\section{Results}

\subsection{Description of the Sample}

A total of 103 students participated in at least one session of the Deadly Choices program across all six groups. The study population consisted of 65 participants in the intervention group and 14 participants in the control group. Demographic data was available for all participants in the study population.

The control group participants were from grade eight, compared with the intervention group who ranged from grade seven to 12. As shown in Table 2, the mean age for participants in the intervention group was 14.8, compared with 12.9 years in the control group. For the intervention group, $67.7 \%$ of participants were male and $32.3 \%$ were female; for the control group, $37.5 \%$ of participants were male and $62.5 \%$ were female. The Deadly Choices program was targeted at Indigenous students, however at some education facilities, non-Indigenous participants also participated in the program. Therefore, the majority of participants were of Indigenous identity.

\subsection{Exploring Health Knowledge, Attitudes and Self-Efficacy}

Baseline comparability between the intervention and control schools was examined, with no significant difference found between groups for any knowledge questions. For questions relating to attitudes and self-efficacy, the intervention group was significantly more confident in having a health check, at baseline $(\mathrm{P} \leq 0.001)$. As detailed in Table 3, for the intervention group, the majority of scores relating to knowledge significantly improved between baseline and follow-up. For questions relating to attitudes and self-efficacy, there was a significant increase for all outcome variables post-program for the intervention group.

Post-program, the intervention group had significantly higher knowledge than the control group for questions regarding types of chronic disease $(\mathrm{P} \leq 0.001)$, chronic disease risk factors $(\mathrm{P}=0.045)$, health conditions caused by smoking $(\mathrm{P}=0.006)$ and the sugar content of soft-drink $(\mathrm{P}=0.009)$. In addition, the intervention group was significantly more confident in preventing chronic disease $(\mathrm{P}=0.005)$ and having a health check $(\mathrm{P} \leq 0.001)$ compared with the control group participants.

\subsection{Self-Reported Health Behaviours}

There were no statistically significant differences between the control and intervention group at baseline for all

\begin{tabular}{|ccc|}
\hline Table 2. Baseline participant characteristics. & & \\
\hline & Intervention (n = 65) & Control (n = 16) \\
\hline Age in years (mean; standard deviation) & $14.8(1.9)$ & $12.9(0.5)$ \\
Gender (\%) & & \\
Male & $67.7 \%$ & $37.5 \%$ \\
Female & $32.3 \%$ & $62.5 \%$ \\
Identity (\%) & & \\
Aboriginal & $84.6 \%$ & $87.5 \%$ \\
Torres Strait Islander & $1.5 \%$ & $6.3 \%$ \\
Both & $0 \%$ & $6.3 \%$ \\
Other & $13.8 \%$ & $0 \%$ \\
\hline
\end{tabular}

Note: Due to rounding, not all percentages add up to $100 \%$. 
Table 3. Knowledge, attitudes and self-efficacy scores.

\begin{tabular}{|c|c|c|c|c|}
\hline Variable & $\begin{array}{l}\text { Pre-Program; } \\
\text { mean (SD) }\end{array}$ & $\begin{array}{c}\text { Post-Program } \\
\text {; mean (SD) }\end{array}$ & $\begin{array}{l}\text { Within group change; } \\
\text { mean difference ( } 95 \% \mathrm{CI})\end{array}$ & $\begin{array}{l}\text { Between group change; mean difference } \\
\qquad(95 \% \mathrm{CI})\end{array}$ \\
\hline \multicolumn{5}{|l|}{ Knowledge $^{1}$} \\
\hline \multicolumn{5}{|c|}{ Elements of Good leadership } \\
\hline Control & $7.3(1.0)$ & $7.4(0.8)$ & 0.06 ( -0.47 to 0.58$) ; \mathrm{P}=0.828$ & \\
\hline Intervention & $7.5(0.9)$ & $7.7(0.7)$ & $0.17(-0.07$ to 0.41$) ; \mathrm{P}=0.174$ & 0.35 ( -0.13 to 0.83 ); $\mathrm{P}=0.153$ \\
\hline \multicolumn{5}{|c|}{ Types of Chronic Diseases } \\
\hline Control & $8.1(2.5)$ & $9.5(2.3)$ & 1.37 (0.18 to 2.56$) ; \mathrm{P}=0.024^{*}$ & \\
\hline Intervention & $9.0(2.1)$ & $12.1(2.2)$ & 2.88 (2.30 to 3.47$) ; \mathrm{P} \leq 0.001^{* *}$ & 2.56 (1.31 to 3.82$) ; \mathrm{P}=<0.001^{* *}$ \\
\hline \multicolumn{5}{|c|}{ Chronic Disease Risk Factors } \\
\hline Control & $8.1(1.8)$ & $7.9(2.0)$ & -0.13 ( -1.45 to 1.19$) ; \mathrm{P}=0.848$ & \\
\hline Intervention & $8.3(2.0)$ & $9.1(1.8)$ & 0.65 (0.03 to 1.28$) ; \mathrm{P}=0.040^{*}$ & 1.13 (0.23 to 2.23 ); $\mathrm{P}=0.045^{*}$ \\
\hline \multicolumn{5}{|c|}{$\begin{array}{l}\text { Health Conditions caused } \\
\text { by smoking }\end{array}$} \\
\hline Control & $7.1(1.0)$ & $7.2(1.3)$ & $0.16(-0.59$ to 0.91$) ; \mathrm{P}=0.671$ & \\
\hline Intervention & $7.2(1.5)$ & $8.4(1.2)$ & 0.96 ( 0.57 to 1.35 ); $\mathrm{P} \leq 0.001^{* *}$ & 1.10 (0.32 to 1.87$) ; \mathrm{P}=0.006^{* *}$ \\
\hline \multicolumn{5}{|c|}{ Types of Physical Activities } \\
\hline Control & $8.1(1.6)$ & $12.2(1.8)$ & 4.17 (3.02 to 5.31 ); $\mathrm{P} \leq 0.001^{* *}$ & \\
\hline Intervention & $7.4(2.5)$ & $12.5(2.1)$ & 3.95 (3.15 to 4.75 ); $\mathrm{P} \leq 0.001^{* *}$ & 0.20 (-1.10 to 1.50$) ; \mathrm{P}=0.765$ \\
\hline \multicolumn{5}{|c|}{ Components of a health check } \\
\hline Control & $6.3(1.1)$ & $6.3(1.05)$ & 0.04 ( -0.65 to 0.74$) ; \mathrm{P}=0.906$ & \\
\hline Intervention & $6.1(1.1)$ & $6.9(1.0)$ & 0.54 ( 0.18 to 0.89 ); $\mathrm{P}=0.003^{* *}$ & 0.58 (-0.03 to 1.19$) ; \mathrm{P}=0.061$ \\
\hline \multicolumn{5}{|l|}{ Sugar in Soft-drink } \\
\hline Control (\%) & 33.3 & 46.7 & $\mathrm{OR}=1.75(0.40$ to 7.66$) ; \mathrm{P}=0.46$ & \\
\hline Intervention (\%) & 38.5 & 81.8 & $\mathrm{OR}=8.11$ (2.95 to 22.30$) ; \mathrm{P} \leq 0.001^{* *}$ & $\mathrm{OR}=5.14$ (1.51 to 17.49$) ; \mathrm{P}=0.009^{* *}$ \\
\hline \multicolumn{5}{|c|}{ Attitudes and Self-efficacy ${ }^{2}$} \\
\hline \multicolumn{5}{|c|}{ Leadership confidence } \\
\hline Control & $3.3(0.8)$ & $3.3(1.0)$ & 0.067 ( -0.44 to 0.58 ); $\mathrm{P}=0.797$ & \\
\hline Intervention & $3.3(1.0)$ & $3.9(0.7)$ & 0.48 ( 0.25 to 0.72$) ; \mathrm{P} \leq 0.001^{* *}$ & 0.42 ( -0.07 to 0.93$) ; \mathrm{P}=0.093$ \\
\hline \multicolumn{5}{|c|}{$\begin{array}{l}\text { Confidence in preventing } \\
\text { Chronic Disease }\end{array}$} \\
\hline Control & $3.5(0.9)$ & $3.5(1.2)$ & -0.07 (-0.69 to 0.56$) ; \mathrm{P}=831$ & \\
\hline Intervention & $3.3(1.1)$ & $4.3(0.8)$ & 0.96 (0.65 to 1.27$) ; \mathrm{P} \leq 0.001^{* *}$ & 0.81 (0.24 to 1.37 ); $\mathrm{P}=0.005^{* *}$ \\
\hline \multicolumn{5}{|c|}{$\begin{array}{l}\text { Comfortable having } \\
\text { a health check }\end{array}$} \\
\hline Control & $2.9(0.96)$ & $3.4(1.0)$ & 0.46 ( -0.09 to 1.01$) ; \mathrm{P}=0.100$ & \\
\hline Intervention & $3.9(1.1)$ & $4.4(0.7)$ & 0.50 (0.23 to 0.76$) ; \mathrm{P} \leq 0.001^{* *}$ & 0.99 (0.46 to 1.52 ); $\mathrm{P} \leq 0.001^{* *}$ \\
\hline \multicolumn{5}{|c|}{ Importance of healthy eating } \\
\hline Control & $9.0(1.5)$ & $8.5(1.6)$ & $-0.50(-1.40$ to -0.41$) ; \mathrm{P}=0.280$ & \\
\hline
\end{tabular}


Continued

\begin{tabular}{cllll}
\hline $\begin{array}{c}\text { Intervention } \\
\text { Importance of physical activity }\end{array}$ & & & & \\
Control & $9.2)$ & $9.4(1.1)$ & $0.81(0.36$ to 1.25$) ; \mathrm{P} \leq 0.001^{* *}$ & $0.86(-0.11$ to 1.83$) ; \mathrm{P}=0.081$ \\
Intervention & $9.0(1.5)$ & $9.1(1.0)$ & $0.03(-0.59$ to 0.65$) ; \mathrm{P}=0.929$ \\
& $9.0(1.5)$ & $9.5(1.0)$ & $0.45(0.15$ to 0.74$) ; \mathrm{P}=0.003^{* *}$ & $0.42(-0.32$ to 1.16$) ; \mathrm{P}=0.264$ \\
\hline
\end{tabular}

${ }^{* *}$ Significant at $0.01 ;{ }^{*}$ significant at 0.05 . OR = Binary outcomes assessed using odds ratios. ${ }^{1}$ Knowledge questions 1 - 6 were scored out of $8,14,10$, 10, 14 and 8 respectively; a higher score denotes better results. Question 7 was multiple-choice. ${ }^{2}$ Attitudes/self-efficacy questions 1 - 3 were scored on a 5-point Likert scale; questions 4 and 5 were scored on a 10-point numerical scale. For both scales, a higher score denotes better results.

behaviour questions. As detailed in Table 4, for the control group, there was a significant decrease in breakfast frequency per week $(\mathrm{P}=0.047)$. For the intervention group there was a significant increase in breakfast $(\mathrm{P}=$ $0.002)$ and physical activity frequency per week $(\mathrm{P} \leq 0.001)$, and fruit $(\mathrm{P}=0.004)$ and vegetable $(\mathrm{P} \leq 0.001)$ consumption per day between baseline and follow-up.

Results were also obtained regarding smoking status and alcohol, cannabis and sniffing behaviours in the past month. For the control group, all participants indicated they were non-smokers and did not consume alcohol or use harmful substances in the past month, at both stages of evaluation. Within the intervention group, $18.5 \%$ of participants smoked cigarettes pre-program, compared with $10.3 \%$ post-program $(\mathrm{P}=0.22) ; 11.4 \%$ used cannabis pre-program, compared with 7.6\% post-program ( $\mathrm{P}=0.44)$; $32.9 \%$ consumed alcohol (within the past month) pre-program, compared with $32.8 \%$ post program $(\mathrm{P}=0.80)$; and $1.3 \%$ engaged in sniffing pre-program, compared with $3.0 \%$ post-program $(\mathrm{P}=0.47)$. Regarding health checks, $49 \%$ of participants from the intervention group reported not having a health check prior to participating in the program; post program $36.7 \%$ of these participants had engaged in a health check. In total, 30 participants received a health check as part of the Deadly Choices program.

Following the intervention, there was a significant difference between the control and intervention group regarding breakfast frequency $(\mathrm{P}=0.042$ ). However, no significant difference was seen between the intervention and control group post-program, regarding sharing health information with others, physical activity, takeaway and soft-drink frequency, daily fruit and vegetable intake, activity levels at school or on the weekends and active mode of transport to school. However some outcomes were in the hypothesized direction (Table 4).

\section{Discussion}

The Deadly Choices program was successful in improving knowledge, attitudes and self-efficacy regarding leadership, chronic disease and risk factors, with a number of significant changes observed in these domains among students who undertook the Deadly Choices program. There were also significant post-program differences between the control and intervention groups for a number of questions regarding knowledge and self-efficacy. Within the intervention group, participants increased their confidence regarding leadership ability which is important; as empowering young Indigenous people to be strong health leaders and agents of change is vital for wider community health and development [25]. Changes between the start and end of the program suggest the program was very promising in terms of improving the health behaviours of these young people, particularly in the areas of diet (breakfast, fruit and vegetables), physical activity and the uptake of health checks. Another encouraging finding of the study was the reduction in smoking rates from $18.5 \%$ to $10.3 \%$, given the reported difficulties in reducing adolescent smoking behaviours in other Australian studies [26]. The positive quantitative findings from this study regarding improved knowledge, attitudes, self-efficacy and behaviours are also supported by the qualitative interview data which is described elsewhere.

Despite these positive within-group behavioural changes, the study showed few significant differences between the control and intervention group regarding behavioural outcomes. Overall, these results are consistent with other school-based studies reported nationally and internationally; that have found significant increases in the health knowledge, attitudes or self-efficacy of students, however mostly low to modest improvements regarding health behaviours [18] [26] [27]. Regardless of this, the findings provide important baseline information regarding health behaviours, which is currently lacking in health research for urban-dwelling Indigenous young people [4]. Results indicate scope for improving a number of health behaviours, for example, the consumption of alcohol and noncore food/drink such as soft drink and take-away foods. To achieve more substantial changes 
Table 4. Behaviour scores.

\begin{tabular}{|c|c|c|c|c|}
\hline Variable & $\begin{array}{l}\text { Pre-Program; } \\
\text { mean (SD) }\end{array}$ & $\begin{array}{l}\text { Post-Program; } \\
\text { mean (SD) }\end{array}$ & $\begin{array}{c}\text { Within group change; } \\
\text { mean difference }(95 \% \mathrm{CI})\end{array}$ & $\begin{array}{l}\text { Between group change; } \\
\text { mean difference }(95 \% \mathrm{CI})\end{array}$ \\
\hline \multicolumn{5}{|l|}{ Behaviours } \\
\hline \multicolumn{5}{|c|}{$\begin{array}{c}\text { Sharing health } \\
\text { information with others }{ }^{1}\end{array}$} \\
\hline Control & $2.1(0.7)$ & $2.3(0.6)$ & $0.2(-0.16$ to 0.59$) ; \mathrm{P}=0.259$ & \\
\hline Intervention & $2.3(0.9)$ & $2.1(0.8)$ & $-0.1(-0.28$ to 0.05$) ; \mathrm{P}=0.179$ & $-0.2(-0.64$ to 0.27$) ; \mathrm{P}=0.431$ \\
\hline \multicolumn{5}{|c|}{ Breakfast (days/week) } \\
\hline Control & $4.7(2.5)$ & $3.4(2.4)$ & $-1.1(-2.14$ to -0.01$) ; \mathrm{P}=0.047^{*}$ & \\
\hline Intervention & $4.5(2.9)$ & $5.3(2.4)$ & 0.7 (0.27 to 1.14$) ; \mathrm{P}=0.002^{* *}$ & 1.5 (0.05 to 2.98$) ; \mathrm{P}=0.042^{*}$ \\
\hline \multicolumn{5}{|c|}{ Take-away food (days/week) } \\
\hline Control & $0.8(0.8)$ & $0.8(0.8)$ & $0.1(-0.62$ to 0.81$) ; \mathrm{P}=0.791$ & \\
\hline Intervention & $1.4(1.3)$ & $1.6(1.6)$ & $0.2(-0.18$ to 0.49$) ; \mathrm{P}=0.365$ & $0.68(-0.13$ to 1.49$) ; \mathrm{P}=0.098$ \\
\hline \multicolumn{5}{|c|}{ Soft-drink (days/week) } \\
\hline Control & $1.7(1.8)$ & $1.5(1.5)$ & 0.20 ( -0.68 to 1.07$) ; \mathrm{P}=0.657$ & \\
\hline Intervention & $2.6(2.3)$ & $2.6(2.2)$ & -0.04 ( -0.50 to 0.42$) ; \mathrm{P}=0.862$ & $0.78(-0.40$ to 1.96$) ; \mathrm{P}=0.197$ \\
\hline \multicolumn{5}{|c|}{ Fruit intake (serves/day) } \\
\hline Control & $2.2(1.3)$ & $2.3(1.4)$ & 0.23 ( -0.47 to 0.93$) ; \mathrm{P}=0.521$ & \\
\hline Intervention & $2.4(1.5)$ & $2.9(1.4)$ & 0.45 (0.15 to 0.76$) ; \mathrm{P}=0.004^{* *}$ & $0.49(-0.29$ to 1.27$) ; \mathrm{P}=0.220$ \\
\hline \multicolumn{5}{|c|}{$\begin{array}{l}\text { Vegetable intake } \\
\text { (serves/day) }\end{array}$} \\
\hline Control & $2.6(1.6)$ & $3.3(1.3)$ & 0.59 ( -0.14 to 1.32$) ; \mathrm{P}=0.116$ & \\
\hline Intervention & $2.7(1.6)$ & $3.8(1.3)$ & 1.09 (0.73 to 1.45$) ; \mathrm{P} \leq 0.001^{* *}$ & $0.63(-0.18$ to 1.45$) ; \mathrm{P}=0.127$ \\
\hline \multicolumn{5}{|c|}{$\begin{array}{l}\text { Physical activity } \\
\text { (days/week) }\end{array}$} \\
\hline Control & $3.9(1.9)$ & $3.8(1.6)$ & 0.002 ( -0.87 to 0.87$) ; \mathrm{P}=0.997$ & \\
\hline Intervention & $3.3(2.1)$ & $4.2(2.0)$ & 0.77 (0.38 to 1.16 ); $\mathrm{P} \leq 0.001^{* *}$ & 0.32 ( -0.82 to 1.46$) ; \mathrm{P}=0.577$ \\
\hline \multicolumn{5}{|c|}{$\begin{array}{c}\text { Active mode of transport } \\
\text { to school \% }\end{array}$} \\
\hline Control & 12.5 & 28.6 & $\mathrm{OR}=16.65$ ( 0.40 to 697.47$) ; \mathrm{P}=0.140$ & \\
\hline Intervention & 34.9 & 42.6 & $\mathrm{OR}=1.28$ ( 0.39 to 4.22$) ; \mathrm{P}=0.681$ & $\mathrm{OR}=7.03(0.20$ to 253.70$) ; \mathrm{P}=0.286$ \\
\hline \multicolumn{5}{|c|}{ Very active at school \% } \\
\hline Control & 31.2 & 14.3 & $\mathrm{OR}=0.08(0.004$ to 1.70$) ; \mathrm{P}=0.106$ & \\
\hline Intervention & 39.1 & 50.0 & $\mathrm{OR}=1.97(0.68$ to 5.71$) ; \mathrm{P}=0.214$ & $\mathrm{OR}=73.35(2.01$ to 2673.10$) ; \mathrm{P}=1.019$ \\
\hline \multicolumn{5}{|c|}{ Very active on weekends \% } \\
\hline Control & 20.0 & 26.7 & $\mathrm{OR}=1.59(0.21$ to 11.91$) ; \mathrm{P}=0.651$ & \\
\hline Intervention & 45.3 & 52.7 & $\mathrm{OR}=1.68$ (0.72 to 3.92$) ; \mathrm{P}=0.229$ & $\mathrm{OR}=4.48$ (0.78 to 25.57$) ; \mathrm{P}=0.092$ \\
\hline
\end{tabular}

\footnotetext{
${ }^{* *}$ Significant at 0.01 ; ${ }^{*}$ significant at 0.05 . OR = Binary outcomes assessed using odds ratios. ${ }^{1}$ Scored out of $4 ; 1=$ every-day, $4=$ never.
}

regarding health behaviours a longer or more intensive intervention may have been required. In addition, when interpreting these results it is important to consider the various barriers that may impact on the health behaviours 
of Indigenous young people at school and home such as family, financial pressures, racism and other personal factors [14] [28] [29].

The significant increase in physical activity levels within the intervention group indicates the effectiveness of the physical activity component of the program, suggesting the activities were meaningful, relevant and culturally appropriate for this group of young people. Similar to the current study, the Australian Football League's Kickstart program aimed to deliver positive lifestyle messages to Indigenous young people though the promotion of physical activity in a school based program. Qualitative results were positive, with improvements found in the education, attitudes and lifestyle choices of participants [30], suggesting that school-based health education programs which provide opportunities for involvement in physical activity have the potential to engage students and promote positive health and lifestyle choices for Indigenous young people. However it is also important to note that the Deadly Choices program focussed its physical activities on participation rather than expertise, recognising that not all Indigenous young people engage in or enjoy sports and physical activity [29]. Therefore school-based health promotion initiatives should offer a diverse range of opportunities to convey these health messages, based on the assets and strengths of young people.

One innovative feature of the Deadly Choices program is that participants were given the opportunity to have a health check at the conclusion of the program, and as a direct result 30 participants completed a health check. Health checks for Indigenous people offer a comprehensive physical and psychosocial health assessment and have the potential to diagnose and address undetected diseases, and provide better treatment of existing diseases [31]. Given the current poor uptake of health assessment items for Australian Indigenous people [32], this approach not only offers a valuable method of encouraging and normalising health checks, but may also help to reduce health inequalities through early identification of health issues. To our knowledge, the Deadly Choices program is the first in Australia to collaborate with local Aboriginal and Torres Strait Islander health services to provide Indigenous health checks in a school-based program. Such partnerships have the potential to maximise health outcomes and chronic disease prevention efforts for Indigenous young people involved in school-based programs.

A number of limitations need to be taken into account when drawing study conclusions and in planning for future programs and evaluations. The limitations of this study include the small sample size, particularly for the control group, resulting in limited statistical power to detect changes between the intervention and control group. Another limitation was the relatively short time period of evaluation; a follow-up study after a number of years would provide more specific insights into the long-term impact of the Deadly Choices program on knowledge, attitudes, self-efficacy and behaviours. The use of a non-validated tool to evaluate the quantitative component of the study also provides challenges with the rigour of this evaluation. In addition, self-completion questionnaires were used and thus may be affected by social desirability bias [33]. Research suggests that ensuring anonymity can enhance the accuracy of self-reporting data [34], thus in the present study, researchers used unique identification numbers to ensure participant anonymity. In addition, the baseline characteristics of the control group were dissimilar to the intervention group, and therefore this affected the comparability of responses, particularly for questions relating to harmful substances and smoking where younger participants may not yet be engaging in these activities.

It should be noted that the data was collected from urban Indigenous young people, and therefore cannot be generalised to Indigenous people living in rural or remote communities, or urban Indigenous adults. In addition it is important to note that this data is not truly representative of all urban Indigenous young people, given the heterogeneity of urban Indigenous young people and the circumstances in which they live. However the use of schools and education centres from a range of socio-economic indexes in this paper allows for greater generalisation.

\section{Conclusion}

As chronic diseases remain a major public health concern for Indigenous people in Australia [35], health promotion programs that target the risk factors for chronic disease at a young age have huge potential to improve the overall health of Indigenous Australians and reduce health inequalities. Results from this study indicate that comprehensive school-based programs, which include education in leadership and chronic disease prevention; engage students in physical activity participation; and facilitate health checks, have great potential to improve the health knowledge, attitudes, self-efficacy and behaviours of young people. However, it is essential that fu- 
ture health promotion initiatives aimed at Indigenous young people utilise a strengths-based approach and consider the wider contexts and environments which may prevent the uptake of health promoting behaviours.

\section{Acknowledgements}

This research project was supported by a Lowitja Institute Cooperative research centre small grant.

\section{References}

[1] O’Dea, K. (2005) Preventable Chronic Diseases among Indigenous Australians: The Need for a Comprehensive National Approach. Heart, Lung and Circulation, 14, 167-171. http://dx.doi.org/10.1016/j.hlc.2005.06.004

[2] Vos, T., Barker, B., Begg, S., Stanley, L. and Lopez, A.D. (2009) Burden of Disease and Injury in Aboriginal and Torres Strait Islander Peoples: The Indigenous Health Gap. International Journal of Epidemiology, 38, 470-477. http://dx.doi.org/10.1093/ije/dyn240

[3] Australian Health Ministers' Advisory Council (2012) Aboriginal and Torres Strait Islander Health Performance Framework 2012 Report. AHMAC, Canberra.

[4] Azzopardi, P.S., Kennedy, E.C., Patton, G.C., Power, R., Roseby, R.D., Sawyer, S.M., Brown, A.D. (2013) The Quality of Health Research for Young Indigenous Australians: Systematic Review. Medical Journal of Australia, 199, 57-63. http://dx.doi.org/10.5694/mja12.11141

[5] AIHW (2011) The Health and Welfare of Australia’s Aboriginal and Torres Strait Islander People: An Overview: 2011. Australian Institute of Health and Welfare, Canberra.

[6] Taggart, J., Williams, A.M., Dennis, S.M., Newall, A.T., Shortus, T.D., Zwar, N.A., Denney-Wilson, E. and Harris, M.F. (2012) A Systematic Review of Interventions in Primary Care to Improve Health Literacy for Chronic Disease Behavioral Risk Factors. BMC Family Practice, 13, 49. http://dx.doi.org/10.1186/1471-2296-13-49

[7] Carson, B., Dunbar, T., Chenhall, R.D. and Baillie, R. (2007) Social Determinants of Indigenous Health. Allen \& Unwin, Sydney.

[8] Mũkoma, W. and Flisher, A.J. (2004) Evaluations of Health Promoting Schools: A Review of Nine Studies. Health Promotion International, 19, 357-368. http://dx.doi.org/10.1093/heapro/dah309

[9] Rowling, L. (2009) Strengthening "School” in School Mental Health Promotion. Health Education, 109, 357-368. http://dx.doi.org/10.1108/09654280910970929

[10] Fung, C., Kuhle, S., Lu, C., Purcell, M., Schwartz, M., Storey, K. and Veugelers, P.J. (2012) From "Best Practice” to "Next Practice": The Effectiveness of School-Based Health Promotion in Improving Healthy Eating and Physical Activity and Preventing Childhood Obesity. International Journal of Behavioral Nutrition and Physical Activity, 9, 27. http://dx.doi.org/10.1186/1479-5868-9-27

[11] Wyn, J., Cahill, H., Holdsworth, R., Rowling, L. and Carson, S. (2000) Mind Matters, a Whole-School Approach Promoting Mental Health and Wellbeing. Australian and New Zealand Journal of Psychiatry, 34, 594-601. http://dx.doi.org/10.1080/j.1440-1614.2000.00748.x

[12] McCuaig, L. and Nelson, A. (2012) Engaging Indigenous Students through School-based Health Education. Australian Institute of Health and Welfare, Canberra.

[13] Lubans, D., Morgan, P., Dewar, D., Collins, C., Plotnikoff, R., Okely, A., Batterham, M., Finn, T. and Callister, R. (2010) The Nutrition and Enjoyable Activity for Teen Girls (NEAT girls) Randomized Controlled Trial for Adolescent Girls from Disadvantaged Secondary Schools: Rationale, Study Protocol, and Baseline Results. BMC Public Health, 10, 652. http://dx.doi.org/10.1186/1471-2458-10-652

[14] Priest, N., Mackean, T., Davis, E., Waters, E. and Briggs, L. (2012) Strengths and Challenges for Koori Kids: Harder for Koori Kids, Koori Kids Doing Well-Exploring Aboriginal Perspectives on Social Determinants of Aboriginal Child Health and Wellbeing. Health Sociology Review, 21, 165-179. http://dx.doi.org/10.5172/hesr.2012.21.2.165

[15] Brough, M., Bond, C. and Hunt, J. (2004) Strong in the City: Towards a Strength-Based Approach in Indigenous Health Promotion. Health Promotion Journal of Australia, 15, 215-220.

[16] Katz, D.L., O’Connell, M., Njike, V.Y., Yeh, M.C. and Nawaz, H. (2008) Strategies for the Prevention and Control of Obesity in the School Setting: Systematic Review and Meta-Analysis. International Journal of Obesity, 32, 1780-1789. http://dx.doi.org/10.1038/ijo.2008.158

[17] Brown, T. and Summerbell, C. (2009) Systematic Review of School-Based Interventions That Focus on Changing Dietary Intake and Physical Activity Levels to Prevent Childhood Obesity: An Update to the Obesity Guidance Produced by the National Institute for Health and Clinical Excellence. Obesity Reviews, 10, 110-141.

http://dx.doi.org/10.1111/j.1467-789X.2008.00515.x 
[18] De Bourdeaudhuij, I., Van Cauwenberghe, E., Spittaels, H., Oppert, J.M., Rostami, C., Brug, J., Van Lenthe, F., Lobstein, T. and Maes, L. (2011) School-Based Interventions Promoting Both Physical Activity and Healthy Eating in Europe: A Systematic Review within the HOPE Project. Obesity Reviews, 12, 205-216. http://dx.doi.org/10.1111/j.1467-789X.2009.00711.x

[19] Clifford, A., Pulver, L.J., Richmond, R., Shakeshaft, A. and Ivers, R. (2011) Smoking, Nutrition, Alcohol and Physical Activity Interventions Targeting Indigenous Australians: Rigorous Evaluations and New Directions Needed. Australian and New Zealand Journal of Public Health, 35, 38-46. http://dx.doi.org/10.1111/j.1753-6405.2010.00631.x

[20] Nelson, A., Macdonald, D. and Abbott, R. (2012) A Risky Business? Health and Physical Activity from the Perspectives of Urban Australian Indigenous Young People. Health, Risk \& Society, 14, 325-340. http://dx.doi.org/10.1080/13698575.2012.680949

[21] Australian Bureau of Statistics (2011) Census of Population and Housing: Socio-Economic Indexes for Areas (SEIFA), Australia. http://www.abs.gov.au/ausstats/abs@.nsf/mf/2033.0.55.001/

[22] Australian Bureau of Statistics (2011) Greater Brisbane (GCCSA). http://www.censusdata.abs.gov.au/census_services/getproduct/census/2011/quickstat/3GBRI

[23] Brisbane City Council (2013) Economic Development. http://www.brisbane.qld.gov.au/about-council/governance-strategy/economic-development/index.htm

[24] Parker, E., Meiklejohn, B., Patterson, C., Edwards, K., Preece, C., Shuter, P. and Gould, T. (2006) Our Games Our Health: A Cultural Asset for Promoting Health in Indigenous Communities. Health Promotion Journal of Australia, 17, 103-108. http://dx.doi.org/10.1093/her/cyf048

[25] CoA (2010) Community Matters Draft 2010. http://www.mindmatters.edu.au/verve/ resources/Community Matters complete draft manuscript v1.pdf

[26] Schofield, M.J., Lynagh, M. and Mishra, G. (2003) Evaluation of a Health Promoting Schools Program to Reduce Smoking in Australian Secondary Schools. Health Education Research, 18, 678-692. http://dx.doi.org/10.1093/her/cyf048

[27] Kerr, J.C., Valois, R.F., Farber, N.B., Vanable, P.A., Di Clemente, R.J., Salazar, L., et al. (2013) Effects of Promoting Health among Teens on Dietary, Physical Activity, and Substance Use Knowledge and Behaviors for African American Adolescents. American Journal of Health Education, 44, 191-202. http://dx.doi.org/10.1080/19325037.2013.798218

[28] Abbott, R., Jenkins, D., Haswell-Elkins, M., Fell, K., MacDonald, D. and Cerin, E. (2008) Physical Activity of Young People in the Torres Strait and Northern Peninsula Region: an Exploratory Study. Australian Journal of Rural Health, 16, 278-282. http://dx.doi.org/10.1111/j.1440-1584.2008.00979.x

[29] Nelson, A. (2009) Sport, Physical Activity and Urban Indigenous Young People. Australian Aboriginal Studies, 2, 101-111.

[30] Dinan-Thompson, M., Sellwood, J. and Carless, F. (2008) A Kickstart to Life: Australian Football League as a Medium for Promoting Life Skills in Cape York Indigenous Communities. Australian Journal of Indigenous Education, 37, 152-164.

[31] Digiacomo, M., Abbott, P., Davison, J., Moore, L. and Davidson, P.M. (2010) Facilitating Uptake of Aboriginal Adult Health Checks through Community Engagement and Health Promotion. Quality in Primary Care, 18, 57-64.

[32] Jennings, W., Spurling, G.K. and Askew, D.A. (2013) Yarning about Health Checks: Barriers and Enablers in an Urban Aboriginal Medical Service. Australian Journal of Primary Health. http://dx.doi.org/10.1071/PY12138

[33] Brener, N.D., Billy, J.O. and Grady, W.R. (2003) Assessment of Factors Affecting the Validity of Self-Reported Health-Risk Behavior among Adolescents: Evidence from the Scientific Literature. Journal of Adolescent Health, 33, 436-457. http://dx.doi.org/10.1016/S1054-139X(03)00052-1

[34] Winchester, L., Rissel, C., Bauman, A. and Dobbinson, S. (1996) Anonymous Record Linkage Using RespondentGenerated Identification Codes-A Tool for Health Promotion Research. Health Promotion Journal of Australia, 6, $52-54$.

[35] Aspin, C., Brown, N., Jowsey, T., Yen, L. and Leeder, S. (2012) Strategic Approaches to Enhanced Health Service Delivery for Aboriginal and Torres Strait Islander People with Chronic Illness: A Qualitative Study. BMC Health Services Research, 12, 143. http://dx.doi.org/10.1186/1472-6963-12-143 